\title{
UTILIZATION OF INDUSTRIAL COMMUNITY 4.0 PLATFORM TO SUPPORT THE SOCIALIZATION OF NATURAL DISASTER MITIGATION BASED ON COMMUNITY ACTIVITIES
}

\author{
Wahyu Sardjono, and Widhilaga Gia Perdana \\ Bina Nusantara University, Indonesia \\ Universitas Indonesia, Indonesia. \\ wahyu.s@binus.ac.id
}

\begin{abstract}
As we know, global industry has experienced three revolutions. It began with the invention of the steam engine in the 1800 s which encouraged mechanization in industry where human and animal power were replaced by engines. The second industrial revolution was marked by the invention of the power plant and combustion chamber. And the third industrial revolution occurred with the advent of digital technology and the internet. The fourth phase of the industrial revolution utilizes the digitalization and use of the internet that took place in the phase of the third revolution. The method of implementing activities in the form of knowledge transfer or capacity building of those who play a role in building an understanding of the industrial community

4.0 to be more monitored and measurable in optimizing sustainable dissemination, becomes important for further implementation. through the development of a Knowledge Management System (KMS) to support the dissemination and internalization of understanding of the community-based industrial revolution, including the development of dissemination and measurement of its performance. An example of the substance used in the development of this knowledge management system is natural disaster mitigation
\end{abstract}

Keywords: Industrial Community 4.0, Socialization, Natural Disaster, Mitigation, Community Activity

\section{INTRODUCTION}

Lately we often hear the new terminology of the Industrial Revolution 4.0 (RI. 4.0). World-class consulting companies such as KPMG, PwC, Boston Consulting create white papers that contain descriptions and directions about RI. 4.0 Many mass media review RI. 4.0 in the form of news or opinion. Not only that, in Indonesia, President Jokowi and several ministers also often discussed it on various occasions at formal meetings. Academic forums have also begun to frequently and seriously discuss them.

The fourth industrial revolution (RI. 4.0) will revolutionize the industry in a fundamental way, so that many jobs will no longer exist in the next 25 years. RI. 4.0 carry out digitization processes in business processes throughout the company's organization. Not only that, products and business models are also digitalized. As an illustration of this digitization process, it is ultimately expected that factory machines can move and work independently in order to produce goods according to user needs in real-time. And when this machine gets information from goods that are in the consumer, this machine will be able to learn and then make new products according to consumer needs. Through the concept of Knowledge Management Systems which are technologies that support organizations in managing their knowledge, this concept helps to identify business processes and subsequently provides a basis for defining collaborative systems between Information Systems and knowledge management. [1] define that KMS refers to an information system class that is applied to manage organizational knowledge, and is developed to support and improve the process of knowledge creation, storage and retrieval, transfer and application in an organization [2]. Therefore, Knowledge Management Systems is an IT-based system developed to support and improve organizational processes of organizational knowledge creation, storage, transfer and application. [3] extends the concept of information technology to Knowledge Management Systems with the definition that Knowledge Management Systems is a comprehensive ICT platform for collaboration and knowledge sharing with advanced knowledge services built on contextualized and integrated on a disseminated ontology basis, and personalized for participants. which is connected to the community. Understanding related to the 
industrial revolution 4.0 can be built through the use of knowledge management systems that are built for various user roles, such as participants, facilitators, managers, and administrators, as well as being equipped with control functions, evaluations, and performance measurements of the success of measurable socialization processes as targeted.

\section{RESEARCH METHODOLOGY}

Knowledge Management

Information is a set of facts and images, while knowledge consists of views and interpretations, which are personalized and refer to specific situations. In addition, what is called information is determined by the recipient, not the sender. Information flows both formally (eg memos, etc.) and informally in organizations. While knowledge is derived from the mind at work, where knowledge can be a process or a stock. Knowledge includes: comparisons between situations, consequences and connections that allow individuals to connect parts of knowledge (information) to other parts.

The knowledge and information equation according to [4] that knowledge is an overview of information; a subset of information; related or specific adjusted to a domain, or work, or to achieve a business goal. While the difference is that information is very general, covers a wide scope; information can be collected, analyzed, but cannot be internalized, while knowledge can be internalized (tacit), built within the individual. In this sense, knowledge can be linked to information that is internalized and capable of (actionable).

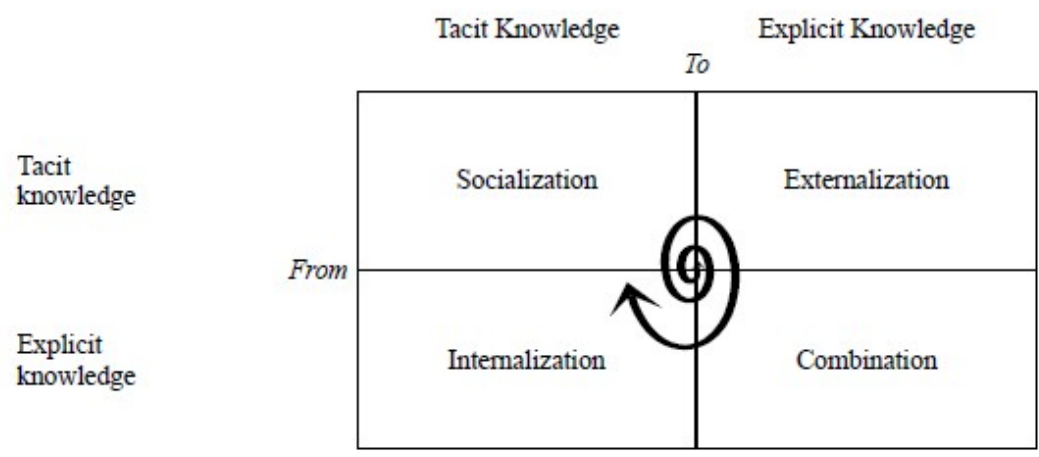

Figure 1. Modes of Knowledge Creation Process (Source: Nonaka, Ikujiro. 1994)

\section{Knowledge Management Systems (KMS)}

The concept of KMS is technologies that support organizations that include: knowledge generation, codification and knowledge transfer [5]. This concept helps identify several KMS functions and is subsequently used to define similar systems such as Collaborative Systems, Information Systems and KMS. [6] explained that KMS refers to the contribution of information systems implemented to manage organizational knowledge, then developed to support and improve the process of creating, storing and retrieving knowledge, transfers and applications in an organization and its dissemination [7]. Therefore, KMS is an information technology-based system developed to support and improve the knowledge management process that is owned by the organization for the innovation of the creation, storage, transfer, and application of existing knowledge to the organization. [8] extends the concept of information technology and incorporates it into KMS by defining that KMS is a comprehensive information technology platform for collaboration and knowledge sharing with advanced level of knowledge services built on contextualization and integrated ontologically, and personally disseminated for connected participants into the community [9].

The process of developing a system based on the Knowledge Management System Life Cycle is a process framework consisting of a repository of knowledge, relationships, Information Technology, communication infrastructure, functional expertise, environment, organizational intelligence and external resources [10]. Knowledge Management System Life Cycle is a cycle that is carried out when an organization starts implementing Knowledge Management System as a medium to accommodate the knowledge possessed by employees [11]. The cycle covered by the Life Cycle Knowledge Management System itself is started from creating or gaining knowledge to spreading the knowledge itself. [12] 


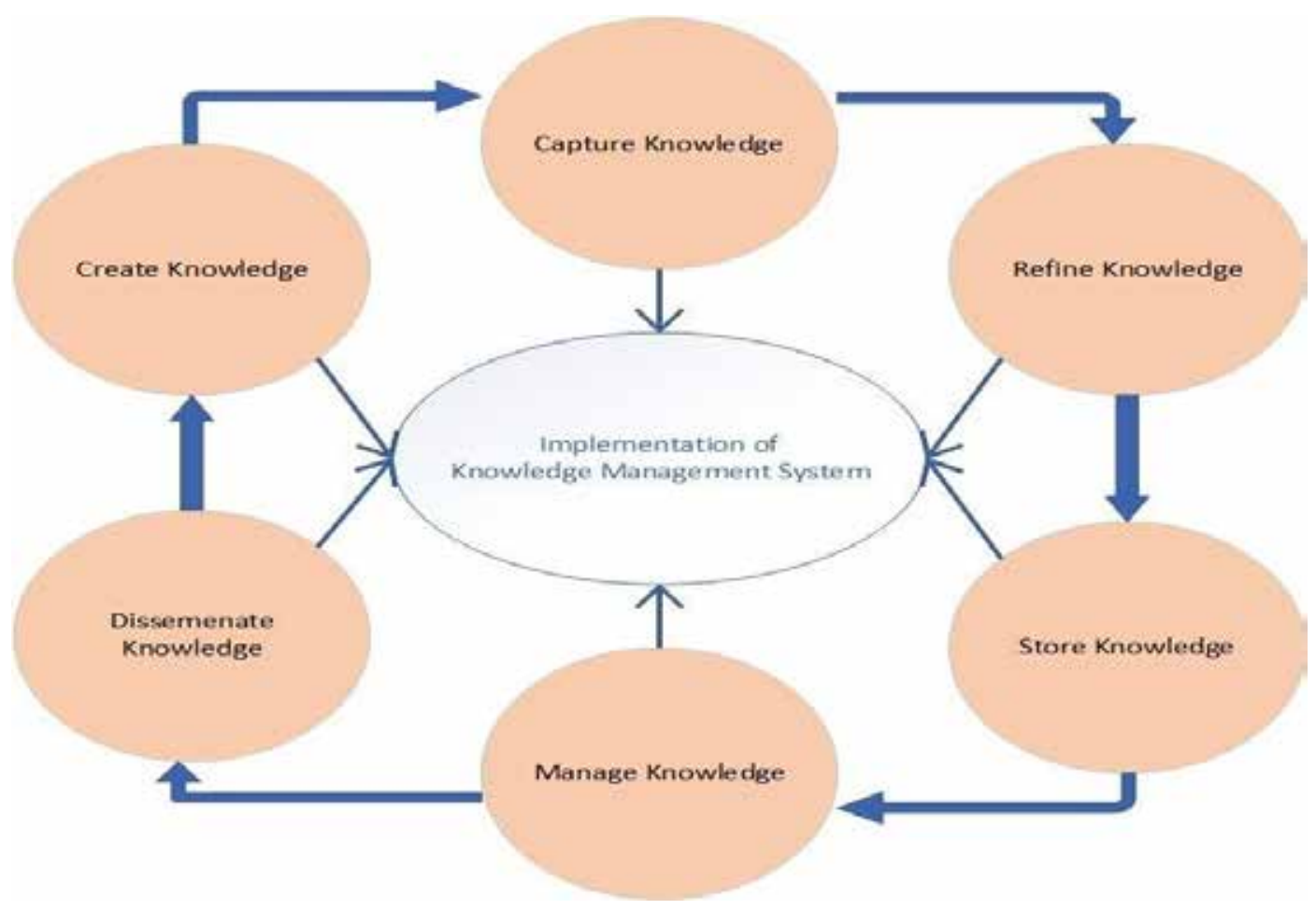

Figure 2. Knowledge Management System Life Cycle (Source: Turban, Sharda, Delen, 2011)

\section{RESULT AND DISCUSSION}

Create Knowledge

The result of the development of the knowledge management system cycle, in the first stage is determining what substances are to be raised or discussed in an interactive portal and here the substance raised is about natural disaster mitigation because of The threat of earthquake hazard spreads in almost all regions of the Indonesian Archipelago, both on a small scale up to destructive large scale, so it needs to be socialized to the whole community for sustainable mitigation. Figure 3.

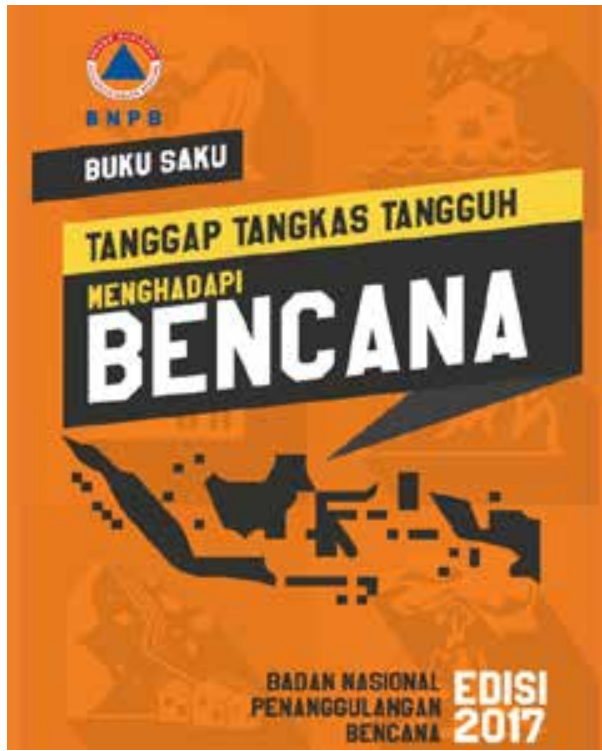

Figure 3. Knowledge of Natural Disaster Mitigation 
Capture knowledge

In the second stage of the development of the knowledge management cycle that must be carried out is to capture knowledge, which is the activity of searching or gathering knowledge or looking for other references related to the completeness of knowledge that we have previously set to be raised, namely about natural disaster mitigation. Figure 4.

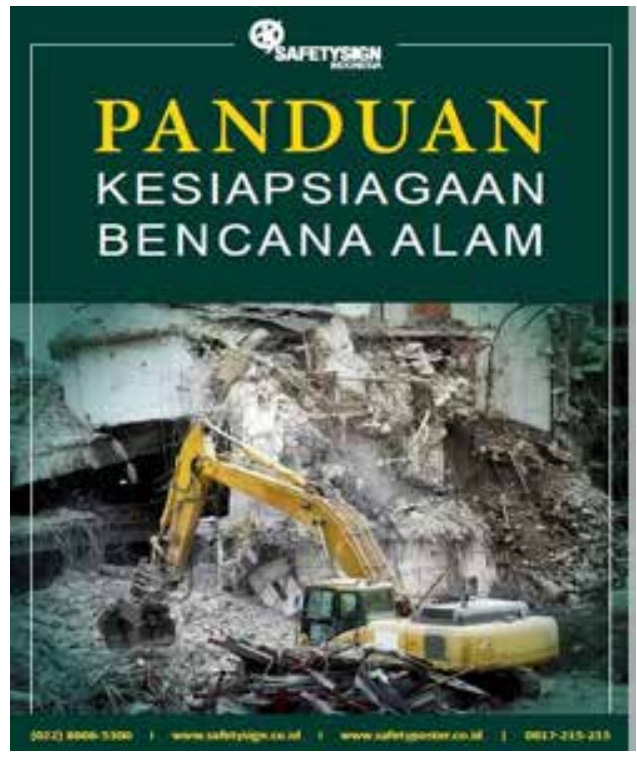

Figure 4. Complete Knowledge of Natural Disaster Mitigation

\section{Refine Knowledge}

In the third stage of the development of the knowledge management cycle is to further process all available documents or references so that they are contained and become comprehensive and appropriate information to be informed to the communities they want to go to. In general, all information must be made in a concise but concise manner and equipped with good narration, supporting images and made clear by the presence of video or motion pictures. refer to Law Number 24 Year 2007 concerning Disaster Management mentions the government central and local governments are responsible implementation of disaster management. Figure 5.

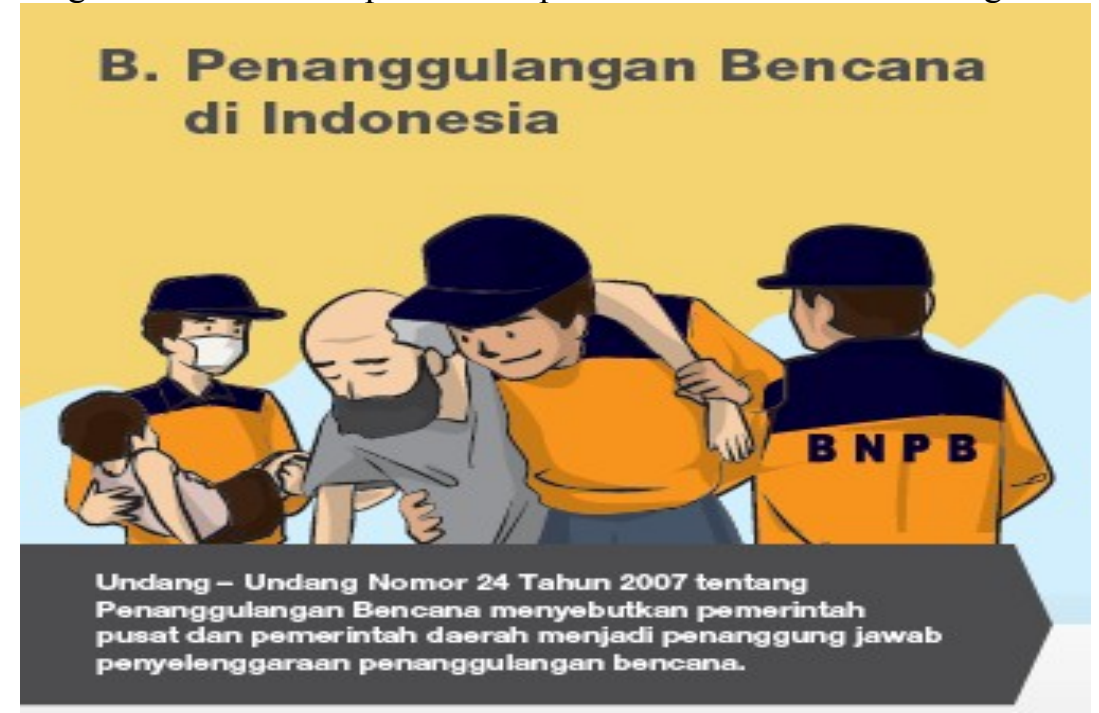

Figure 5. Law Number 24 Year 2007 concerning Disaster Management mentions the government central and local governments are responsible implementation of disaster management 


\section{Store Kowledge}

In the fourth stage of the development of the knowledge management system cycle is store knowledge, which places knowledge that has been well managed so that it can later be disseminated and easy to follow and act upon by the community. At this stage needed tools or information technology platforms that can support the socialization process that is effective and efficient based on participants. Here can be exemplified the formation of the portal www.green-indonesia.org, Figure 6.

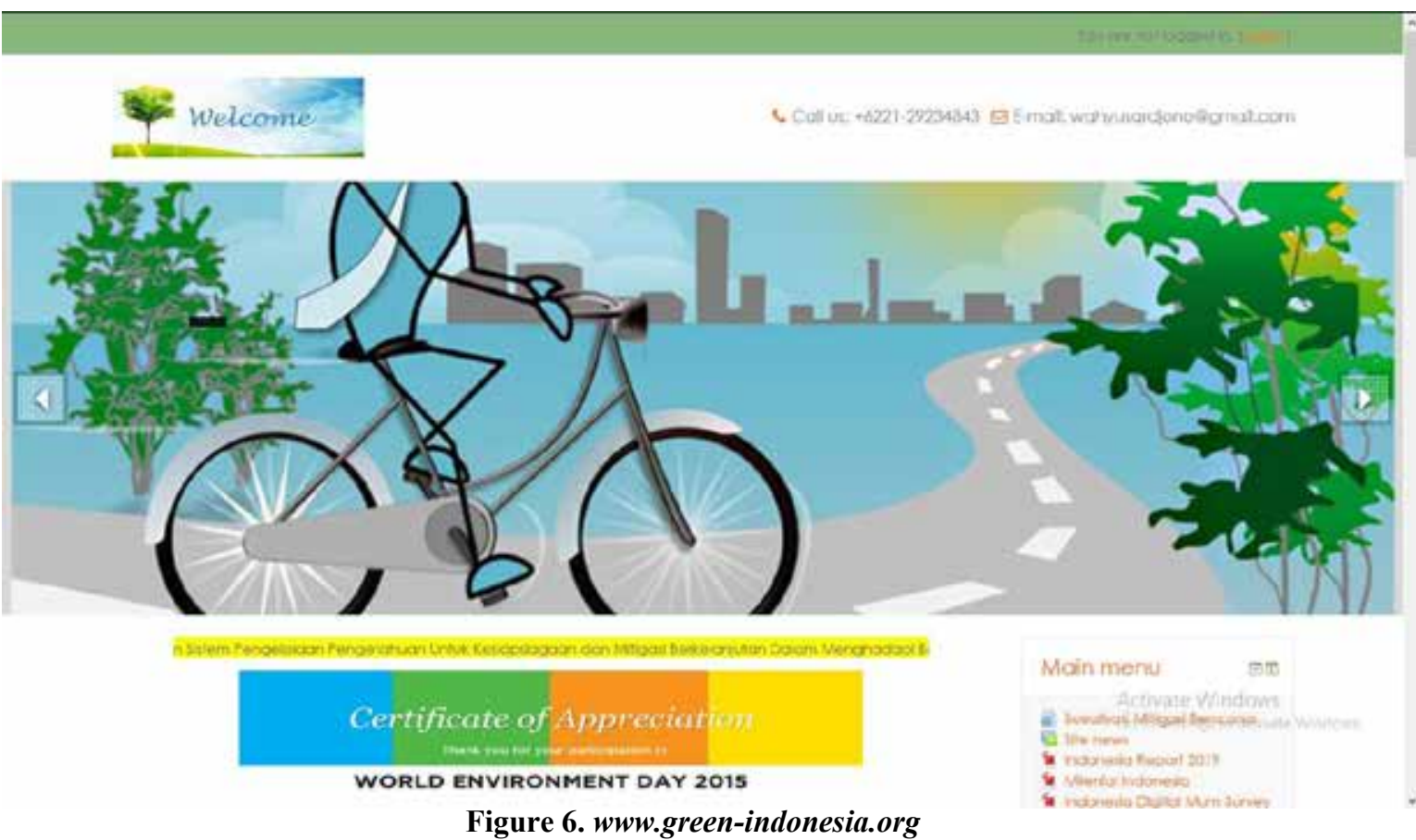

Manage Knowledge

Next in the fifth stage of the development of the knowledge management system cycle is managing knowledge, which is an activity to prepare how to evaluate the understanding of knowledge that has been well managed so that later it can be monitored and controlled for its performance, even the results of evaluation and feedback can be easily by the community. At this stage a good understanding direction is needed so that people want to read and learn about the substance given, namely natural disaster mitigation, it is hoped that the community can measure itself to the extent that their understanding has been sufficient to recognize all aspects related to natural disasters. Figure.7

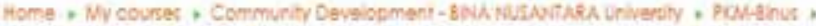

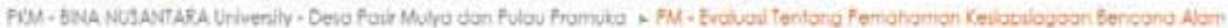
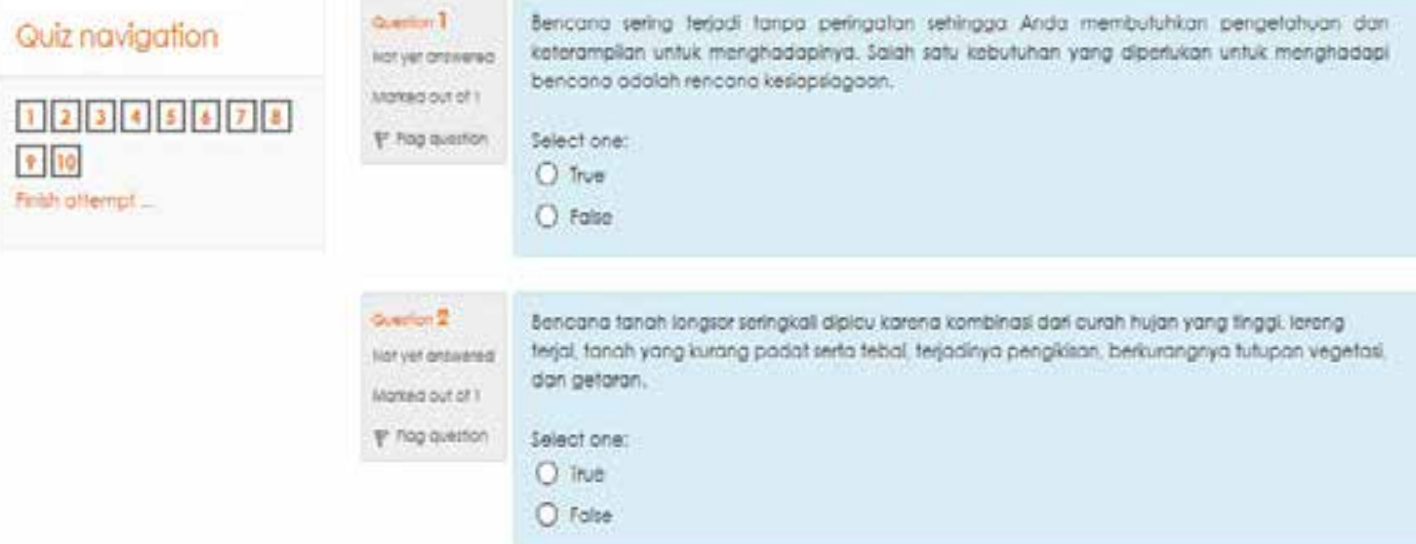

Figure 7. Evaluating Understanding of Natural Disaster Mitigation 


\section{Disseminate Knowledge}

The last stage of developing the knowledge management system cycle is disseminate knowledge, which is an activity to disseminate knowledge directly that can be utilized as an independent learning activity by utilizing information systems and technology. Evaluation of understanding the knowledge that has been well managed, can automatically be done by working on the direction of the evaluation or quizzes provided. This process can be carried out repeatedly until a value of 100 (one hundred) is reached which identifies the understanding is complete, so that it is ready and can anticipate existing conditions. Figure 8. shows some participants who have succeeded very well in learning or understanding knowledge about natural disaster mitigation independently.

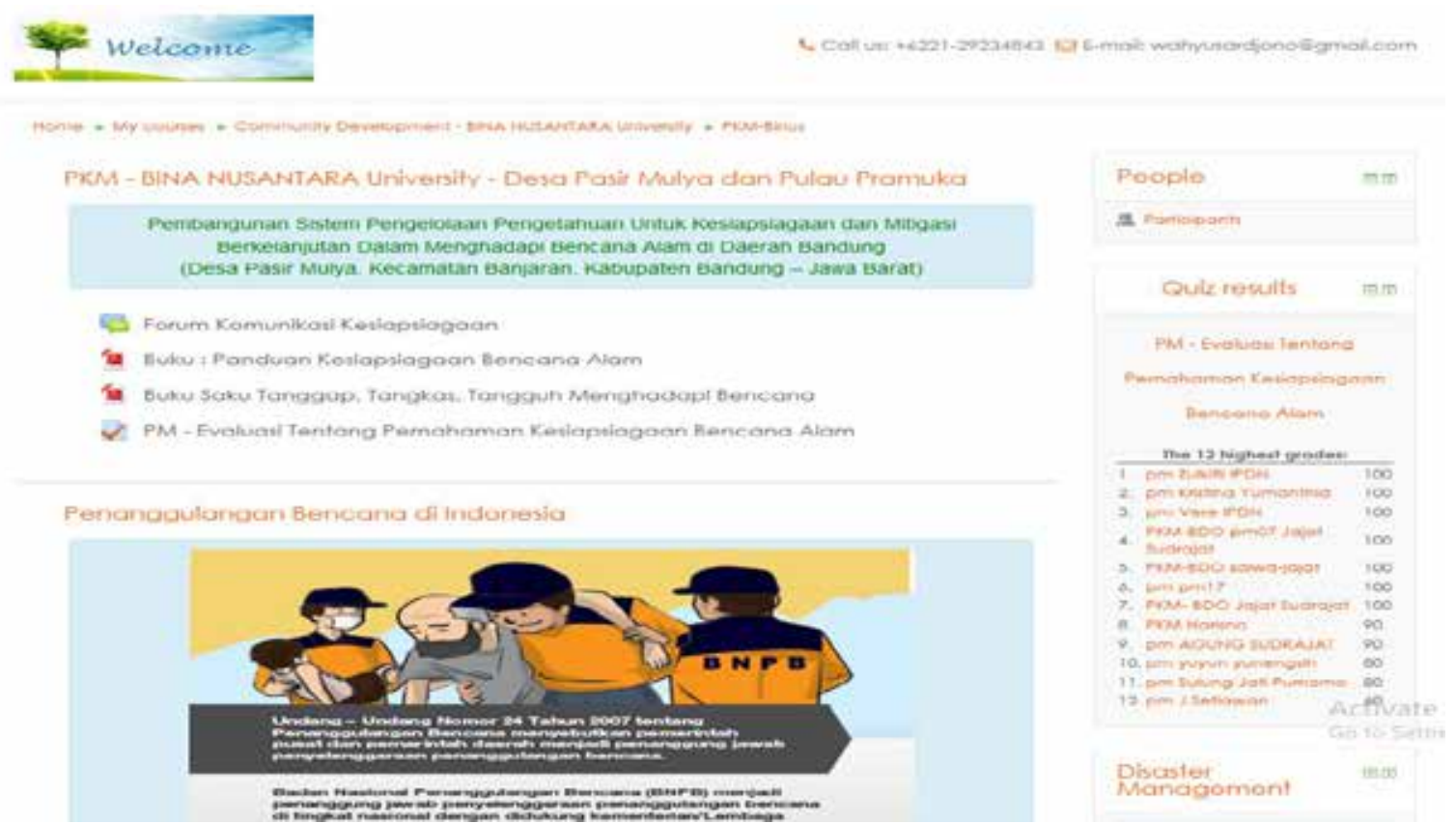

Figure 8. Dissemination Result of Natural Disaster Mitigation

The results of the implementation of a knowledge management system for the socialization of natural disaster mitigation have been carried out trials on the Pramuka island of the thousand islands, Panggang Island of the thousand isllands, the Pasir Mulya village - Banjaran Bandung, and Cempaka Mulya Vilage - Banjaran Bandung. With a very positive response from the local village communities,

\section{CONCLUSION}

From the results of the above explanation it can be concluded that:

1. The industrial community era 4.0 is a technology platform that has globally entered communities at various levels wherever the community is located.

2. Information technology platform in industry 4.0 can be used for various purposes of socialization related to government policies or regulations for the benefit of the community.

3. Socialization of sustainable natural disaster mitigation can continue to be developed independently by utilizing the industrial information technology platform 4.0

4. The optimal use of Industry 4.0 can support community activities to become more effective and efficient so that competitive advantage is achieved for increasing social capacity in various communities, both those who live in urban and rural areas.

\section{ACKNOWLEDGEMENT}

The authors would like to thank BINUS University, Indonesia and the Community Service Internal Grant Program in 2019 which has funded the development of knowledge management systems for the socialization of mitigation of natural disasters by building prototypes for the Masyarakat Desa Pasir Mulya West of Java. 


\section{REFERENCES}

[1] Celina M. Olszak, Tomasz Bartuś, Paweł Lorek. (2018). A comprehensive framework of information system design to provide organizational creativity support. $\square$ Information \& Management, Volume 55, Issue 1, January 2018, Pages 94-108

[2] Wu, J.H., \& Wang, Y.M. (2006). Measuring KMS success: a respecification of the DeLone and McLean's model, Information \& Management

[3] Maier, Ronald. 2006. Knowledge Management Systems, Springer-Verlag

[4] Kamran Munir, M. Sheraz Anjum. (2018). The use of ontologies for effective knowledge modelling and information retrieval. Applied Computing and Informatics, Volume 14, Issue 2, July 2018, Pages 116 126

[5] Esther, Carmen. Allan, Watt. Laurence, Carvalho. Jan, Dick. Ioan, Fazey. Gemma, Garcia Blanco. Jennifer, Hauck. Zita Izakovicova. Leena, Kopperoinen. Camino, ZitaIzakovicova. Leena, Kopperoinen. Camino, Liquete.David, Odee. Eveliene, Steingröver. Juliette, Young. (2018). Knowledge needs for the operationalisation of the concept of ecosystem services. Ecosystem Services, Volume 29, Part C, February 2018, Pages 441-451.

[6] Alavi, M., \& D.Leidner. 2002. Review: Knowledge management and knowledge management systems: Conceptual foundations and research issues. MISQ, 25(1)

[7] Fangcheng Tang, Jifeng Mu, Douglas L. MacLachlan. (2010). Disseminative capacity, organizational structure and knowledge transfer. $\quad$ Expert Systems with Applications, Volume 37, Issue 2, March 2010, Pages 1586-1593

[8] Alexandra Klimova, Eric Rondeau, Karl Andersson, Jari Porras, Andrei Rybin, Arkady Zaslavsky. (2016). An international Master's program in green IT as a contribution to sustainable development. Journal of Cleaner Production. Elsevier.

[9] Cesar Bandera, Regina Collins, Katia Passeri ni. (2018). Risky business: Experiential learn ing, in formation and communications techno logy, and risk-taking attitudes in entrepreneur ship education. International Journal of Management Education. Elsevier.

[10] Harijanti, S.D. (2015). 'The changing paradigm on governance: the case of Indonesia', Int.J. Public Law and Policy, Vol. 5, No. 1, pp.77-91.

[11] Kumar, M., Raman, J.and Priya. (2016). 'The effects of green policy on the performance of green supply chains', Int. J. Integrated Supply Management, Vol.10, No.1, p.1-37.

[12] Shahla, Ab Razak CheHussin, Halina MohamedDahlan. (2017). Organizational rese arch in the field of Green IT: A systematic literature review from 2007 to 2016. Telematics and Informatics. Vol. 34, Issue 7, November 2017, Pages 1191-1249. Elsevier. 